\title{
ANALYSIS OF TURBULENT EXCHANGE AND COHERENT STRUCTURES IN THE STABLE ATMOSPHERIC BOUNDARY LAYER BASED ON TOWER OBSERVATIONS
}

\author{
E. Ferreres ${ }^{1}$, M.R. Soler ${ }^{2}$, and E. Terradellas ${ }^{3}$ \\ ${ }^{1}$ Departament de Física Aplicada, Universitat Politècnica de Catalunya, Av. Bases de \\ Manresa, 61-73, 08240 Manresa, Spain \\ ${ }^{2}$ Departament d'Astronomia i Meteorologia, Universitat de Barcelona, Martí i Franquès 1, \\ 08028 Barcelona, Spain \\ ${ }^{3}$ Agencia Estatal de Meteorología, Arquitecte Sert 1, 08005 Barcelona, Spain
}

\author{
Corresponding author \\ M.R.Soler \\ - E-mail address: rosa@am.ub.es \\ - Full postal address: Department of Astronomy and Meteorology, Faculty of Physics, \\ University of Barcelona, 08028 Barcelona, Spain \\ - Phone number: 0034934021129
}

\begin{abstract}
Using data collected at the Spanish low troposphere research centre CIBA (Centro de Investigación de la Baja Atmósfera) and at the Cabauw Experimental Site for Atmospheric Research (CESAR) in the Netherlands, we analysed the most significant features of different coherent structures occurring in the stable atmospheric boundary layer. In particular, we used both the Reynolds and wavelet methods to analyse a solitary wave, a gravity wave, a density current and a low-level jet. For each of these structures, we found that wavelet analysis had the capacity to distinguish the different scales involved in these events due to the different timing and heights of the thermal instabilities and downdrafts associated with the disturbances. In addition, the wavelet method highlights the different roles of turbulence and coherent structures in the transfer of heat, moisture and $\mathrm{CO}_{2}$ in the nocturnal boundary layer.
\end{abstract}

Keywords Coherent structures. Intermittent turbulence. Nocturnal boundary layer. Wavelet Transform

\section{Introduction}

Though much is known about the structure of the convective boundary layer and the physical processes which take place within it, much less is known about the stable boundary layer (SBL), especially as regards what happens under conditions of large static stability and strong vertical wind shear, when turbulence is sporadic and intermittent (Mahrt and Vickers 2002; Nakamura and Mahrt 2005; Mahrt, 2010; Mahrt et al., 2012). Shear instability and subsequent local buoyant overturns are the primary cause of turbulence in stratified boundary layers, which can lead to thermal instability as indicated by the analysis of the vertical microstructure of the stably stratified boundary layer (Sorbjan and Balsley, 
2008; Sun et al., 2012). Reasons for increased turbulence are diverse and may include the intrusion of coherent structures such as gravity waves, density currents (Terradellas et al., 2005) and low-level jets (LLJs) (Mahrt 1999; Newsom and Banta (2003); Cuxart and Jíménez (2007). Although intermittent turbulence has long been recognized as a characteristic of the SBL, it is only in recent years that its interaction with low-frequency (coherent) structures, such as those mentioned above, has become an important subject in boundary-layer research (Sun et al., 2004; Terradellas et al., 2005; Acevedo et al., 2006; Prabha et al., 2007; Sun et al., 2012). The main reason for this interest is that the aforementioned interaction plays an important role in momentum and scalar transport, contributing significantly to turbulent fluxes, which must be accounted for in subgrid-scale parameterizations of mesoscale and global scale numerical weather prediction models (Drobinski et al., 2006; Costa et al., 2011). The interaction of coherent structures with turbulence is evidenced in time series of scalar variables such as air temperature, specific humidity and $\mathrm{CO}_{2}$ concentration by the presence of the following patterns: (i) a gradual fall followed by a sudden rise or (ii) a sudden rise followed by a gradual fall (Foster et al., 2006). There is therefore a clear need to apply appropriate techniques to identify and characterize the coherent structures present in the records of high-frequency measurements performed in the SBL.

This paper reports an investigation of the most significant features of different coherent structures found in the SBL and their effect on related processes such as scalar transfer. The methodology used in this study was based on the wavelet transformation technique, which was applied to large datasets containing measurements performed at different levels at the CIBA and Cabauw meteorological towers (Cuxart et al., 2000; Bosveld et al., 2006).

Wavelet-based methods have proved useful in the analysis of the different scales of motion that are present in the atmospheric boundary layer (ABL) (Terradellas et al., 2001; Cuxart et al., 2002; Terradellas et al., 2005). In particular, in the small-scale turbulence range, these methods provide much better estimations of turbulent moments than the traditional method based on the Reynolds decomposition, since with suitable selection of the mother wavelet, the wavelet transform presents in some cases much better performance as regards filtering out low frequencies. Wavelet methods are especially advantageous in the stable ABL, where the frequent absence of a spectral gap between the turbulent scale and lowfrequency perturbations renders use of the Reynolds decomposition to estimate turbulent kinetic energy or fluxes very problematic (Terradellas et al., 2005). Since wavelet methods yield a time-frequency representation of turbulent moments, they also permit analysis of the evolution over time of the contribution of different scales, in contrast to the Reynolds method where this spectral analysis is only possible for selected time periods.

This paper is organized as follows. Data collection and a description of the wavelet method are presented in sections 2 and 3. Selected cases from the CIBA and Cabauw data are examined, analysed and discussed in section 4, with particular emphasis on assessment of the information obtained using the wavelet method. Some final conclusions are given in section 5 .

\section{Description of the research sites and data}


The data used in this study were collected at the CIBA (Centro de Investigación de la Baja Atmósfera, Spain) facilities and at the Cabauw Experimental Site for Atmospheric Research (CESAR, The Netherlands).

The CIBA is located in the central area of the Upper Duero basin, at $41^{\circ} 49^{\prime} \mathrm{N}, 4^{\circ} 56^{\prime} \mathrm{W}$; it sits on a small plateau known as Montes Torozos, a flat area of $800 \mathrm{~km}^{2}$ lying at $840 \mathrm{~m}$ above sea level (and approximately $50 \mathrm{~m}$ above the surrounding flat land) and covered by grain crops. Several atmospheric boundary layer experiments have been performed there, e.g. SABLES98 (Cuxart et al., 2000) and SABLES2006 (Yaguie et al., 2007), the objectives of which were to study the properties and typical features of the nocturnal stably-stratified boundary layer (NBL), such as intermittent turbulence, slope flows, down-valley winds, LLJs and gravity waves (Cuxart et al., 2000; Terradellas et al., 2001; Cuxart, 2008; Bravo et al., 2008; Viana et al., 2007, 2009; Udina et al., 2013).

The Duero basin is surrounded by high mountain ranges at a distance of approximately 100 $\mathrm{km}$ to the north, east and south of the site, with the river flowing westwards towards the Atlantic. Its central part is flat to the eye, but has gentle slopes (less than $1^{\circ}$ ) leading down to the Duero river. The Torozos plateau has a gentle downward slope of about $30 \mathrm{~m}$ along a stretch of $50 \mathrm{~km}$ from the north-east to the south-west, with the north-west and south-east borders slightly above the level of the inner plateau.

The following data, gathered between September 2002 and June 2003 by different instruments mounted on a 100-m mast, were retrieved from the CIBA database:

- wind speed at 2.2, 9.6, 34.6, 74.6 and $98.6 \mathrm{~m}$ above ground level (AGL)

- $\quad$ wind direction at 9.6, 34.6, 74.6 and 98.6 m AGL

- air temperature at 2.3, 10.5, 20.5, 35.5 and $97.5 \mathrm{~m}$ AGL

- air humidity at 10 and 97 m AGL.

In addition, wind and temperature measured by sonic anemometers set at 5.6, 19.6, 49.6 and $96.6 \mathrm{~m} \mathrm{AGL}$ at a frequency of $20 \mathrm{~Hz}$, as well as turbulent fluctuations computed from the records were used. A detailed description of the calculation of fluctuations can be found in Conangla et al. (2008).

The Cabauw $213 \mathrm{~m}$ meteorological tower is located in the western part of The Netherlands $\left(51^{\circ} 58^{\prime} \mathrm{N} 4^{\circ} 56^{\prime}\right.$ E $0.7 \mathrm{~m}$ above sea level), approximately $50 \mathrm{~km}$ east of the North Sea and $1 \mathrm{~km}$ northwest of the Lek river. Its main facility is an instrumented $213-\mathrm{m}$ tower. The site lies in an open field almost completely covered by short grass, which extends for several hundred metres in all directions. The immediate surroundings of the tower have been described in detail in several papers (i.e. Van Ulden and Wieringa, 1996; Beljaars and Bosveld, 1997).

Vertical profiles of wind velocity, air temperature and humidity, and carbon dioxide concentration between August 2003 and August 2004 were considered. Measurements of $\mathrm{CO}_{2}$ concentration have been described by Werner et al. (2006). The following records were used:

- air temperature and specific humidity at 2, 10, 20, 40, 80, 140 and $200 \mathrm{~m}$ AGL

- wind velocity and direction at 10, 20, 40, 80, 140 and 200 m AGL 
- $\mathrm{CO}_{2}$ concentration at $20,60,120$ and $200 \mathrm{~m}$ AGL.

- Turbulent fluxes of momentum, sensible heat, latent heat and $\mathrm{CO}_{2}$ concentration at 5, 60, 100 and $180 \mathrm{~m}$ AGL

All flux sensors were sampled at $10 \mathrm{~Hz}$. A detailed description of flux measurements can be found in Bosveld et al. (2004) and Werner et al. (2006).

\section{Wavelet Methods}

In this section, we summarize the wavelet tools that we used in the present study to estimate kinetic energy and fluxes from time series of high-frequency meteorological data recorded under stable conditions.

A description of the wavelet theory and some application methods can be found in many reference works (Daubechies, 1992; Farge, 1992; Meyers et al., 1993; Lau and Weng, 1995; Torrence and Compo, 1998; Labat, 2005).

From the general principle that the wavelet transform fulfils energy conservation for the whole series (Farge, 1992; Mallat, 1998), Terradellas et al. (2001) defined the energy density per time and scale unit of the time-series $f(t)$ at the scale $s$ and time $t_{0}$ as:

$\left\langle f^{2}>_{s t_{0}}=\frac{2}{C_{\Psi}} \frac{\left\|F_{s t_{0}}\right\|^{2}}{s^{2}}\right.$

with

$$
C_{\Psi}=2 \Pi \int_{-\infty}^{\infty} \frac{d \zeta}{|\zeta|}|\overline{\Psi(\zeta)}|^{2}
$$

where $F_{s t_{0}}$ is the wavelet transform of the function $\mathrm{f}(\mathrm{t})$ at the scale $\mathrm{s}$ and time $\mathrm{t}_{0}$ and $\overline{\Psi(\zeta)}$ is the Fourier transform of the mother wavelet. The integration over time and scales of equation (3) for time series of wind components allows estimation of turbulent kinetic energy.

Similarly, Cuxart et al. (2002) defined what can be considered as the flux density:

$$
<f g>_{s t_{0}}=\frac{2}{C_{\Psi}} \frac{F_{s t_{0}} G_{s t_{0}}}{s^{2}}
$$

where $(*)$ denotes complex conjugation.

Integration of equation (3) allows estimation of turbulent fluxes.

In the present study, the Morlet function - a plane wave with a Gaussian modulation - was chosen, because it is well suited to the analysis of series with oscillatory behaviour. Its expression is: 


$$
\Psi_{s t_{0}}(t)=\frac{1}{\sqrt[4]{\Pi}} \frac{1}{\sqrt{|s|}} e^{i \omega_{0}\left(\frac{t-t_{0}}{s}\right)} e^{-\frac{1}{2}\left(\frac{t-t_{0}}{s}\right)^{2}}
$$

where $\omega_{0}$ is a non-dimensional parameter, usually called base frequency.

The scale is not the most appropriate magnitude to define the characteristics of an oscillation, because its value is meaningful only when associated with a particular mother wavelet. Meyers et al. (1993) derived the relationship between scale and equivalent Fourier period for the Morlet wavelet:

$$
T=\frac{1}{f}=\frac{4 \Pi s}{\omega_{0}+\sqrt{2+\omega_{0}^{2}}}
$$

Introducing this expression to equations (1) and (3), the specific contribution of a period to the total energy or flux is:

$$
\begin{aligned}
& \left\langle f^{2}>_{T t_{0}}=\left\langle f^{2}>_{s t_{0}}\left|\frac{d s}{d T}\right|=\frac{1}{C_{\Psi}} \frac{8 \Pi}{\omega_{0}+\sqrt{2+\omega_{0}^{2}}} \frac{\left\|F_{s t_{0}}\right\|^{2}}{T^{2}}\right.\right. \\
& <f g>_{T t_{0}}=\left\langle f g>_{s t_{0}}\left|\frac{d s}{d T}\right|=\frac{1}{C_{\Psi}} \frac{8 \Pi}{\omega_{0}+\sqrt{2+\omega_{0}^{2}}} \frac{F_{s t_{0}} G_{s t_{0}}}{T^{2}}\right.
\end{aligned}
$$

\section{Selected cases for the analysis of intermittent turbulence}

After an exhaustive analysis of the CIBA and Cabauw databases, three nocturnal events characterized by intermittent or bursting turbulence were selected. The cases were detect and identified by the existence of an abrupt increase in turbulent kinetic energy and turbulent fluxes (absolute value) calculated by the traditional averaging method based on the Reynolds decomposition of variables into mean and turbulent parts. The retrieved data were then processed using wavelet methods in order to take advantage of one of their most useful attributes: their capacity to provide information on the evolution of the different scales involved in the event. Wavelets are used to simultaneously identify and analyse lowfrequency coherent structures such as gravity or Kelvin-Helmholtz waves, LLJs and density currents, as well as higher-frequency phenomena such as intermittent small-scale turbulence. Knowledge of the dynamics of coherent structures and their interaction with turbulence is essential to improve understanding of the mechanisms that govern the very stable boundary layer.

Reynolds average method is presented as a first part of the analysis because it becomes an easy and a useful method to directly detect from data measurements the presence of coherent structures and its relation with the intermittent turbulence phenomena. However, if the analysis attempts to go deeper, as in this study, separating the contribution of the different spectral ranges to the total energy or the fluxes involved in the coherent structure, 
wavelet method must be used. This is the reason to present both methodologies. Vertical heat fluxes and turbulent kinetic energy calculated with Reynolds average will be reliable and valid when there is small low-frequency activity (Terradellas et al., 2005). The situation is different when most of the energy is produced by large scale oscillations, since the estimation of TKE by the averaging method integrates the TKE and an unknown part of the kinetic energy produced by large period oscillations. Since the vertical heat flux can be either positive or negative, even values with the wrong sign may be obtained. In any case, the comparison of both methods done in this study shows that the presence of large-scale structures always acts in the direction of increasing the turbulent kinetic energy and turbulent fluxes. Therefore, the presence of coherent structures related to high period activity perturb the values of TKE and vertical heat fluxes calculated with Reynolds method and therefore it could be a good technique to detect their presence.

\subsection{Night 9-10 March, 2003 at the CIBA}

The first episode analysed is the night 9-10 March, 2003. The synoptic situation over the Iberian Peninsula was anticyclonic, with small pressure gradients favouring the development of a very stable night and the formation of a LLJ. The records of the measurements performed at the tower show that the LLJ was established around 0130 UTC (Figure 1a), but with a very low persistence. Between 0200 and 0400 UTC, a decrease in the horizontal wind speed at all measurement levels, but most especially at the intermediate levels of $49.6 \mathrm{~m}$ and $74.6 \mathrm{~m}$, caused the LLJ to quickly vanish (Figure 1a). Meanwhile, the wind direction, which was initially southerly, became fluctuating (Figure 1b). Starting at 0400, the wind speed began to increase again, especially at high levels, and the direction became south-easterly. During the period of very low wind conditions, the direction may be questionable if the sensor threshold is the same order of the wind speed. However, sonic anemometers used in the measurements presented in Figures 1a and $1 \mathrm{~b}$ have a threshold for the wind components $\mathrm{u}$ and $\mathrm{v}$ of $15 \mathrm{mms}^{-1}$, and $4 \mathrm{mms}^{-1}$ for $\mathrm{w}$, an accuracy of $\pm 3 \%$ averaged for all directions and a sampling frequency of $20 \mathrm{~Hz}$. The accuracy for wind direction is not provided by the manufacturer, but the performance of the equipment is sufficient to provide reliable measurements of wind direction under weak-wind conditions. The problem could arise when defining a precise mean wind direction to estimate, for instance, the airborne dispersion (Anfossi et al., 2005).

A detailed data analysis of vertical velocity and temperature is shown in Figures 1c and 1d, revealing that the first event, occurring around 0230 UTC, was characterized by large fluctuations in the vertical velocity measured by the sonic anemometers located at 96.6, 49.6, 19.6 and $5.6 \mathrm{~m}$. At 96.6 and $49.6 \mathrm{~m}$, large amplitude oscillations appeared (about 1.2 $\mathrm{ms}^{-1}$ ) while at $19.6 \mathrm{~m}$ and $5.6 \mathrm{~m}$, the disturbance was also discernible but the amplitude decreased to 1 and $0.5 \mathrm{~ms}^{-1}$, respectively. Figure $1 \mathrm{~d}$ also gives the corresponding temperature perturbation records, which showed large fluctuations that were clearly visible at all measured levels but were most evident at the highest ones, indicated by a rapid but transient drop in temperature of close to $5^{\circ} \mathrm{C}$. This temperature disturbance was less marked at intermediate and lower levels, but a transient drop in temperature associated with the disturbance could still be detected. The perturbation manifesting as a solitary gravity wave could be the signature of a classical Benjamin-Davis-Ono (BDO) solitary wave, as it was similar to those observed by Rottman and Einaudi (1993), Rees et al., (1998) and Sun et al., 
(2004). In the atmosphere, the BDO theory applies mainly to low level waves, in which the waves normally propagate in a stable low level layer trapped by a very weakly stratified layer. According to Rees et al. (1998), solitary waves are large amplitude, short disturbances that propagate either singly or as a train of several waves over large distances without a significant change in form. They maintain their shape due to a balance between the nonlinear effects that cause the wave to steepen, and dispersion, which tends to smooth out the wave. It is now believed that moderate amplitude solitary disturbances are commonplace within the atmosphere, and they are usually observed to propagate along nocturnal inversions in the troposphere.

The second event, occurring around 0320 UTC (Figure 1c), was also characterized by large fluctuations in vertical velocity, albeit of a lower amplitude (about $0.6 \mathrm{~ms}^{-1}$ ). Following these initial changes manifested as a solitary wave, all the variables fluctuated, indicating that the disturbance is manifested as a wave packet, clearly evident at the $96.6 \mathrm{~m}$ and $49.6 \mathrm{~m}$ levels and comprising a burst of approximately eight wave periods. The corresponding temperature perturbation record given in Figure 1d is also manifested as a wave packet, and it is signified by a rapid drop in temperature. The estimated Brunt Väisälä frequency during this event was $\mathrm{N}=0.046 \mathrm{~s}^{-1}$, which is higher than the frequency of the observed wave (about $0.002 \mathrm{~s}^{-1}$ ), implying that the observed propagating wave was an internal gravity wave (Gill, 1982).

The origin of all these perturbations is unknown due to the limitations of the spatial coverage, but measurements at all levels of the tower showed that the resulting wind speed and direction during the passage of the internal gravity wave oscillated at all levels. The oscillation of the wind direction presented in Figure $1 b$ and mainly in Figure $2 a$ corresponds to the phenomena called meandering of the wind vector, which can occur with weak large-scale flow. It has been analyzed by several authors as Anfossi et al., (2005), Mahrt (2007) and Mahrt (2008) using sonic anemometers. Although meandering does not have a precise definition or physical understanding, there are several potential causes (Mahrt 2007), including solitary waves and internal gravity waves, as those presented in this paper. Thus, in Figure 2a, which corresponds to the uppermost level of the tower, it can be seen that the wind direction turned from the southern (wind direction prior to the event) to the western sector, Likewise, the wind speed decreased to minimum values when the wind blew from the west, whereas the horizontal wind speed achieved maximum values when wind blew from the southern sector again. At the end of the disturbance period, both variables returned to their former values. Most probably, the arrival of a western current caused horizontal convergence forcing the air to rise and thus causing the air parcel to cool (Figure 2b). However, a parcel of air displaced upwards in the stable boundary layer will encounter a restoring force due to the stability, and the parcel will then accelerate downwards, resulting in the warming of the air parcel (Figure 2b). This process creates the oscillatory behaviour responsible for the development of gravity waves. Figure $2 \mathrm{~b}$ also shows that the vertical velocity oscillation was around 1.8 minutes ahead of the temperature oscillation, which is a quarter of the estimated wave period (about 7 minutes). These results are consistent with linear wave theory, which predicts that vertical velocity and temperature oscillations should be $90^{\circ}$ out of phase. 
The effect of these disturbances can also be seen in the turbulent kinetic energy (TKE) and turbulent sensible heat flux time history (Figures $2 \mathrm{c}$ and $\mathrm{d}$ ) calculated every five minutes using the Reynolds decomposition. The low values of these magnitudes, recorded before the episode, suddenly changed to high values. This turbulent episode lasted until 0400, with some periods of inactivity. As demonstrated by Sun et al. (2004), the turbulence intermittency manifested by an abrupt increase in TKE at 0230 UTC and 0320 UTC at any given level (Figure 2c) was triggered mainly by the occurrence of the events described above, the solitary wave and the gravity wave. Similarly, the turbulent heat flux (Figure 2d) showed how large upward (mainly in the second episode) and downward motions forced cold air over warm air, thus generating regions of thermal instability and resulting in turbulent transfer in the opposite direction to normal transport in the nocturnal boundary layer.

In order to identify the coherent structures associated with these disturbances, we employed the wavelet method described in section 3, using a 6-base-frequency Morlet function with integration up to a 30 min period. Numerical results calculated from data obtained from sonic anemometers located at different levels of the CIBA tower between 0100 UTC and 0530 are presented in Figures 3. Analysis of a detailed time-period representation of kinetic energy density per unit-period (in $\mathrm{m}^{2} \mathrm{~s}^{-3}$ ) (Figure 3a) revealed an elongated structure corresponding to solitary waves and also high values constrained to a relatively narrow range of periods centred at 6.5 minutes, approximately corresponding to the period of the internal gravity wave. This value is consistent with the value deduced from measurements (Figure 2b) corresponding to the time evolution of vertical velocity and temperature oscillations.

As regards sensible heat flux, since vertical velocity and temperature oscillations should be $90^{\circ}$ out of phase, the wave should not contribute to vertical turbulent fluxes. However, the detailed time-period representation of sensible heat flux density per unit-period (in $\mathrm{k} \mathrm{m} \mathrm{s}^{-2}$ ) given in Figure $3 \mathrm{~b}$ shows the disturbance induced by the passage of the internal gravity wave, perturbing the vertical temperature profile and causing positive turbulent fluxes (thermal instability) at smaller scales and a very small negative fluxes at higher scales.

\subsection{Night 28-29 May 2003 at the CIBA}

The second episode analysed is the night 28-29 May, 2003. The synoptic situation over the Iberian Peninsula was dominated by an area of high pressure and a weak horizontal pressure gradient. The night began with a weak north-westerly wind during the early evening which gradually veered to the north-east and east from 2200 UTC to 2400 UTC (Figures $4 a, b)$. Surface radiative cooling favoured the development of a strong temperature inversion of nearly $9^{\circ} \mathrm{C}$ between the surface and the top of the $100 \mathrm{~m}$-mast (Figure 4c). Data from these figures corresponds to cup anemometers and vanes with thresholds of 0.5 $\mathrm{ms}^{-1}$ and $1 \mathrm{~ms}^{-1}$ respectively, and accuracies of $\pm 0.2 \mathrm{~ms}^{-1}$ and $\pm 3^{\circ}$ respectively with a sampling frequency of $5 \mathrm{~Hz}$. For this coherent structure, a density current, the meandering phenomena did not occur, as wind direction did not oscillate and winds over the first levels

of measurement $(2.2 \mathrm{~m})$ were equal or higher than $2 \mathrm{~ms}^{-1}$, especially on the higher levels of the tower. Therefore, wind direction measurements are reliable for these levels. 
Around midnight, there was a sudden onset of southerly winds of moderate speed (about 6 $\mathrm{m} \mathrm{s}^{-1}$ at the top of the mast), and an abruptly and large temperature decrease measured at all levels of the tower except near the surface at $2,2 \mathrm{~m}$. These changes suggest the arrival of a cold gravity current from the southern sector, since this coherent structure is associated with local thermal and shear instabilities (see Figures 4d,e,f) induced by the dynamics of the density current (Einaudi and Finnigan, 1993; Sun et al., 2002).

This episode was also analysed employing the wavelet method described in section 3, using a 6-base-frequency Morlet function with integration up to a $30 \mathrm{~min}$ period. Numerical results calculated from data obtained from sonic anemometers located at different levels of the CIBA tower between 1800 UTC 28 April and 060029 April are presented as a detailed time-period representation of kinetic energy density per unit-period (in $\mathrm{m}^{2} \mathrm{~s}^{-3}$ ) (Figure 5a) and heat flux density per unit-period $\left(\mathrm{k} \mathrm{m} \mathrm{s}^{-2}\right)$ (Figure $5 \mathrm{~b}$ ). The first figure shows several peaks in the region of low periods, which can be attributed to bursts of turbulence, and an elongated coherent structure detected at all levels, the energy of which was spread out over a wide spectral range. The elongated structure, denoting a sudden change in the prevailing conditions (Terradellas et al., 2005), corresponded to a gravity current occurred near 0000 UTC. In addition, the ability of wavelet-based techniques to analyse the separate contribution of different spectral ranges to the total energy or fluxes enabled us to investigate the physical reasons for the alternation sign of the vertical heat flux density per unit-period appearing in Figure 5b, mainly at the higher levels. A plausible explanation of this behaviour in the context of a density current is based on the following conceptual model: a downward-moving cold air parcel warms up adiabatically, reaching and then exceeding its equilibrium level, becoming a downward warm current. Similarly, an upwardmoving warm air parcel cools down adiabatically, exceeds its equilibrium level and becomes an upward cold current. This double circulation is in close agreement with the continuity condition (Terradellas et al., 2005).

\subsection{Evening of 20 April, 2004 at the Cabauw}

The episode analysed corresponds to 20 April, 2004 at the Cabauw site. The synoptic situation over The Netherlands was dominated by an area of high pressure with a weak horizontal pressure gradient. The values recorded for the early evening at the different levels of the Cabauw tower correspond to a typical situation in which intermittent turbulence occurred, generated by the presence of a low level jet. As described by Turner (1973) and Businger (1973), on clear nights over land in presence of weak winds, strong surface radiation may build up a strong surface inversion, as can be seen in Figure 6a, where the temperature at the first measurement level of the tower dropped significantly. Under these conditions, turbulence was almost completely suppressed, causing a decoupling between the atmosphere and the underlying surface, as can be seen in Figure 6a from 1700 UTC to 1830 UTC, approximately. Shortly afterwards however, due to the reduced friction, the air in the lower atmosphere was accelerated by the pressure force, giving rise to a low level jet (LLJ) (Figure 6b), the nose of which was located at between 30 and $40 \mathrm{~m}$ AGL, as can be seen in Figures $6 \mathrm{~b}$ and c. Under these conditions, shear increases, regenerating turbulence and mixing. This could be the reason for the drop in temperature which mainly occurred at the low and intermediate levels, forming a deeper surface inversion (Figure 6a) which increased the height of the stable layer until the nose of the jet rose to approximately $40 \mathrm{~m}$ high. An almost neutrally stratified shear layer lay above the jet, 
as indicated by the potential temperature profiles (not shown) corresponding to the socalled residual layer. In addition, in response to the shear instability associated with the initiation of the LLJ, bursts of turbulence were observed in the time evolution of turbulent kinetic energy and sensible heat, moisture and carbon dioxide fluxes (see Figures 7a,b,c,d), all calculated by the Reynolds method. The turbulence created by the LLJ generated upward and downward motions, leading thermal instability mainly at the height of $100 \mathrm{~m}$, as can be seen in Figure 7.

Elevated turbulence can be generated by shear on the upper side of drainage flows and low level jets, which may be associated with the residual layer which in the early evening is characterized by decaying turbulence from the daytime boundary layer and throughout the night contains weak stratification where modest shear can regenerate turbulence (Mahrt 1999). Several authors as Smedman et al. (1993) Newsom and Banta (2003) meet turbulence and mixing in the upper part of the LLJ, whilst other authors as Conangla and Cuxart, (2006) and Cuxart and Jiménez (2007) meet turbulence between 1 and 3 times the height of the wind maximum due basically to shear production combined with a weak temperature gradient.

This episode was also analysed employing the wavelet method described in section 3, using a 6-base-frequency Morlet function with integration up to a $30 \mathrm{~min}$ period. Results are presented as a detailed time-period representation of vertical sensible heat, latent heat and $\mathrm{CO}_{2}$ density fluxes per unit-period from 1700 UTC to 24 UTC 20 April 2004. Numerical values were calculated from measurement data obtained at the different levels of the Cabauw tower. For this analysis, we used the term co-gradient flux to mean positive vertical flux, and counter-gradient flux to mean negative vertical flux. In the case of heat flux, positive contribution refers to an exchange in which an upward-moving eddy carrying warm, moist and $\mathrm{CO}_{2}$-rich air or a downward-moving eddy carrying cold, dry and $\mathrm{CO}_{2-}$ depleted air contribute to the flux. In a negative contribution, upward-moving cold, dry and $\mathrm{CO}_{2}$-depleted air or downward-moving warm, moist and $\mathrm{CO}_{2}$-rich air causes the exchange. We used the relative importance of the co-gradient and counter-gradient fluxes to isolate the contributions of the different spectral ranges to the vertical sensible heat flux, latent heat flux and $\mathrm{CO}_{2}$ flux presented in the figures below.

In Figures 8a, and in particular the one that corresponds to the vertical heat flux at $5 \mathrm{~m}$ height, it can be seen that the main contribution to the counter-gradient flux at the commencement of the event was for low and high periods (high and low frequency) associated with turbulence and large scale motions, respectively, moving warm air downwards and cold air upwards, respectively, although the flux magnitude was very small. It should be noted that there was a short interval of between 8 and 10 minute periods in which there was a co-gradient heat flux, since the upward transport of cold air over warm cause thermal instability. At $60 \mathrm{~m}$ height, there was a co-gradient contribution to sensible heat flux for turbulence and periods of less than 10 minutes, while counter-gradient fluxes were restricted to larger scales. For the levels of 100 and $180 \mathrm{~m}$, but mainly at $100 \mathrm{~m}$, the exchange of sensible heat was due to co-gradient fluxes at larger scales, while countergradient fluxes were restricted to turbulence and lower periods occurring after the initiation of the jet. These results indicate that sensible heat exchange at low levels is mainly due to counter-gradient fluxes related to small eddies moving cold air upwards or warm air downwards, while at intermediate and higher levels, the exchange is dominated by cogradient fluxes related to medium and larger scales. 
The analysis of vertical latent heat flux (Figure $8 \mathrm{~b}$ ) revealed that there was a countergradient contribution to the latent flux at $60 \mathrm{~m}$ height related to small eddies and those corresponding to periods of less than 10 minutes, which moved moist air downwards and dry air upwards, respectively, while the co-gradient contribution was restricted to very small eddies and those corresponding to periods of between 10 and 18 minutes. Similar behaviour was observed at $100 \mathrm{~m}$ height, while the exchange at $180 \mathrm{~m}$ was mainly due to counter-gradient fluxes at all scales, although the magnitude of the vertical latent heat flux was very small.

In the case of vertical $\mathrm{CO}_{2}$ flux (Figure 8c), the analysis at $60 \mathrm{~m}$ height showed an alternation between co-gradient and counter-gradient contributions to $\mathrm{CO}_{2}$ fluxes for periods of less than 10 minutes, while the co-gradient contribution was for periods of between 12 and 18 minutes, similar to the results corresponding to the exchange of latent heat flux. This is probably related to an upward motion of cold, moist and $\mathrm{CO}_{2}$-rich air or a downward motion of warm, dry and $\mathrm{CO}_{2}$-depleted air, if Figures $8 \mathrm{a}, 8 \mathrm{~b}$ and $8 \mathrm{c}$ are compared. At the levels of $100 \mathrm{~m}$ and $180 \mathrm{~m}$ height, the contribution to co-gradient fluxes was restricted to periods of less than 8 minutes whereas counter-gradient fluxes dominated for periods over 8 minutes.

\section{Conclusions}

Using data collected from the CIBA and Cabauw sites located in Spain and the Netherlands respectively, we have studied the main features of different coherent structures in the stable atmospheric boundary layer. We identified a solitary wave, an internal gravity wave, a density current and a low level jet. The first two structures, detected at the CIBA site, were characterized by large amplitude disturbances, indicated by a rapid drop in temperature and a larger increase in vertical velocity, which was a quarter ahead of the estimated wave period, consistent with linear wave theory. As a result of these disturbances, intermittent turbulence was generated and shown by experimental measurements and wavelet analysis in the range of high frequencies. In addition, wavelet analysis of the internal gravity wave revealed high values of kinetic energy density constrained to a relatively narrow range of high periods, corresponding, as also indicated by observations, with the period of the internal gravity wave.

Wavelet analysis of the third episode, a density current, also occurring at the CIBA site, illustrated and proved that this methodology has the capacity to distinguish the different scales involved in the event due to the different timing and heights of the thermal instabilities and downdrafts associated with this atmospheric disturbance.

Lastly, the results obtained from the analysis of the LLJ occurring at the Cabauw site show an efficient transport of sensible heat, latent heat and $\mathrm{CO}_{2}$, concluding that the presence of this type of jet enhances turbulence and large scale transport not only through the stable boundary layer but also above the jet in the residual layer, in accordance with several authors. Wavelet analysis has demonstrated that the contribution to maximum co-gradient and counter gradient fluxes of sensible heat, latent heat and $\mathrm{CO}_{2}$ occurred at different 
periods and frequencies, indicating that the transport caused by the LLJ generates homogeneity in the scalar fields.

\section{Acknowledgements}

This study was supported by the Spanish government through the project CGL 200912797-C03-03. The authors would like to thank Fred Bosveld (Koninklijk Nederlands Meteorologisch Instituut), Alex Vermeulen (Energieonderzoek Centrum Nederland), Jordi Vilà (University of Wageningen) and the University of Valladolid for their contribution in obtaining the Cabauw and CIBA tower dataset used in this study.

\section{References}

Acevedo, O.C., Moraes, O.L.L., Degrazia, G.A., Medeiros, L.E., 2006. Intermittency and the exchange of scalars in the nocturnal surface layer. Bound. -Layer Meteorol. 119, 41-55.

Anfossi, D., Oettl, D., Degrazia, G., Goulart, A., 2005. An analysis of sonic anemometer observations in low wind speed conditions. Bound. -Layer Meteorol. 114, 179-203.

Beljaars, A., Bosveld, F., 1997. Cabauw data for the validation of land surface parameterization schemes. J. Clim. 10, 1172-1193.

Bosveld, F.C., van Meijgaard, E., Moors, E., Werner, C., 2004. Interpretation of flux observations along the Cabauw 200-m meteorological mast. Proceedings of the 16th AMS conference on Boundary Layer and Turbulence .

Bosveld, F.C., Vermeulen, A., Moors, E., Russchenberg, H., Apituley, A., Uijlenhoet, R., de Leeuw, G., Moene, A., Werner, C., 2006. Atmospheric Boundary Layer Observations at Cabauw in the Netherlands. 17th Symposium on Boundary layers and turbulence San Diego, American Meteorological Society.

Bravo, M., Mira, T., Soler, M.R., Cuxart, J., 2008. Intercomparison and evaluation of MM5 and Meso-NH mesoscale models in the stable boundary layer. Bound. -Layer Meteorol. 128, 77-101.

Businguer, J.A., 1973. Turbulent Transfer in the Atmosphere Surface Layer, Workshop in Micrometeorology ed. Science Press, Boston.

Conangla, L., Cuxart, J., 2006. On the turbulence in the upper part of the low-level jet: An experimental and numerical study. Bound. -Layer Meteorol. 118, 379-400.

Conangla, L., Cuxart, J., Soler, M.R., 2008. Characterisation of the nocturnal boundary layer at a site in northern Spain. Bound. -Layer Meteorol. 128, 255-276.

Costa, F.D., Acevedo, O.C., Mombach, J.C.M., Degrazia, G.A., 2011. A Simplified Model for Intermittent Turbulence in the Nocturnal Boundary Layer. J. Atmos. Sci. 68, 1714-1729.

Cuxart, J., Jimenez, M.A., 2007. Mixing processes in a nocturnal low-level jet: An LES study. J. Atmos. Sci. 64, 1666-1679.

Cuxart, J., Morales, G., Terradellas, E., Yague, C., 2002. Study of coherent structures and estimation of the pressure transport terms for the nocturnal stable boundary layer. Bound. Layer Meteorol. 105, 305-328.

Cuxart, J., Yague, C., Morales, G., Terradellas, E., Orbe, J., Calvo, J., Fernandez, A., Soler, M., Infante, C., Buenestado, P., Espinalt, A., Joergensen, H., Rees, J., Vila, J., Redondo, J., Cantalapiedra, I., Conangla, L., 2000. Stable atmospheric boundary-layer experiment in Spain (SABLES 98): A report. Bound. -Layer Meteorol. 96, 337-370. 
Cuxart, J., 2008. Nocturnal basin low-level jets: an integrated study. Acta Geophysica 56, 100-113.

Daubechies, I., 1992. Ten Lectures on Wavelets. Society for Industrial and Applied Mathematics, Philadelfia.

Drobinski, P., Redelsperger, J., Pietras, C., 2006. Evaluation of a planetary boundary layer subgrid-scale model that accounts for near-surface turbulence anisotropy. Geophys. Res. Lett. 33, L23806.

Einaudi, F., Finnigan, J.J., 1993. Wave-Turbulence Dynamics in the Stably Stratified Boundary-Layer. J. Atmos. Sci. 50, 1841-1864.

Farge, M., 1992. Wavelet Transforms and their Applications to Turbulence. Annu. Rev. Fluid Mech. 24, 395-457.

Foster, D., Beach, R., Holman, R., 2006. Turbulence observations of the nearshore wave bottom boundary layer. Journal of Geophysical Research-Oceans 111, C04011.

Gill, A.E., 1982. Atmosphere-Ocean Dynamics. Academic Press, San Diego.

Labat, D., 2005. Recent advances in wavelet analyses: Part I. A review of concepts. Journal of Hydrology 314, 275-288.

Lau, K.M., Weng, H., 1995. Climate signal detection using wavelet transform: How to make a time series sing. Bull. Am. Meteorol. Soc. 76, 2391-2402.

Mahrt, L., 2010. Common microfronts and other solitary events in the nocturnal boundary layer. Q. J. R. Meteorol. Soc. 136, 1712-1722.

Mahrt, L., 2008. The influence of transient flow distortion on turbulence in stable weak-wind conditions. Bound. -Layer Meteorol. 127, 1-16.

Mahrt, L., 2007. The influence of nonstationarity on the turbulent flux-gradient relationship for stable stratification. Bound. -Layer Meteorol. 125, 245-264.

Mahrt, L., 1999. Stratified atmospheric boundary layers. Bound. -Layer Meteorol. 90, 375396.

Mahrt, L., Richardson, S., Seaman, N., Stauffer, D., 2012. Turbulence in the nocturnal boundary layer with light and variable winds. Q. J. R. Meteorol. Soc. 138, 1430-1439.

Mahrt, L., Vickers, D., 2002. Contrasting vertical structures of nocturnal boundary layers. Bound. -Layer Meteorol. 105, 351-363.

Mallat, S., 1998. A Wavelet Tour of Signal Processing. Academic Press, San Diego.

Meyers, S.D., Kelly, B.G., Obrien, J.J., 1993. An Introduction to Wavelet Analysis in Oceanography and Meteorology - with Application to the Dispersion of Yanai Waves. Mon. Weather Rev. 121, 2858-2866.

Nakamura, R., Mahrt, L., 2005. A study of intermittent turbulence with cases-99 tower measurements. Bound. -Layer Meteorol. 114, 367-387.

Newsom, R.K., Banta, R.M., 2003. Shear-flow instability in the stable nocturnal boundary layer as observed by Doppler lidar during CASES-99. J. Atmos. Sci. 60, 16-33.

Prabha, T.V., Leclerc, M.Y., Karipot, A., Hollinger, D.Y., 2007. Low-frequency effects on eddy covariance fluxes under the influence of a low-level jet. Journal of Applied Meteorology and Climatology 46, 338-352.

Rees, J.M., Anderson, P.S., King, J.C., 1998. Observations of solitary waves in the stable atmospheric boundary layer. Bound. -Layer Meteorol. 86, 47-61.

Rottman, J.W., Einaudi, F., 1993. Solitary Waves in the Atmosphere. J. Atmos. Sci. 50, 2116-2136.

Smedman, A.S., Tjernstrom, M., Hogstrom, U., 1993. Analysis of the Turbulence Structure of a Marine Low-Level Jet. Bound. -Layer Meteorol. 66, 105-126. 
Sorbjan, Z., Balsley, B.B., 2008. Microstructure of turbulence in the stably stratified boundary layer. Bound. -Layer Meteorol. 129, 191-210.

Sun, J.L., Burns, S.P., Lenschow, D.H., Banta, R., Newsom, R., Coulter, R., Frasier, S., Ince, T., Nappo, C., Cuxart, J., Blumen, W., Lee, X., Hu, X.Z., 2002. Intermittent turbulence associated with a density current passage in the stable boundary layer. Bound. -Layer Meteorol. 105, 199-219.

Sun, J., Mahrt, L., Banta, R.M., Pichugina, Y.L., 2012. Turbulence Regimes and Turbulence Intermittency in the Stable Boundary Layer during CASES-99. J. Atmos. Sci. 69, 338-351.

Sun, J., Lenschow, D., Burns, S., Banta, R., Newsom, R., Coulter, R., Frasier, S., Ince, T., Nappo, C., Balsley, B., Jensen, M., Mahrt, L., Miller, D., Skelly, B., 2004. Atmospheric disturbances that generate intermittent turbulence in nocturnal boundary layers. Bound. Layer Meteorol. 110, 255-279.

Terradellas, E., Morales, G., Cuxart, J., Yague, C., 2001. Wavelet methods: application to the study of the stable atmospheric boundary layer under non-stationary conditions. Dyn. Atmos. Oceans 34, 225-244.

Terradellas, E., Soler, M.R., Ferreres, E., Bravo, M., 2005. Analysis of oscillations in the stable atmospheric boundary layer using wavelet methods. Bound. -Layer Meteorol. 114, 489-518.

Torrence, C., Compo, G.P., 1998. A practical guide to wavelet analysis. Bull. Am. Meteorol. Soc. 79, 61-78.

Turner, J.S., 1973. Buoyancy Effects in Fluids. Cambridge University Press, Cambridge.

Udina, M., Soler, M.R., Viana, S., Yaguie, C., 2013. Model simulation of gravity waves triggered by a density current. Q. J. R. Meteorol. Soc. 139, 701-714.

Van Ulden, A.P., Wieringa, J., 1996. Atmospheric boundary layer research at Cabauw. Boundary-Layer Meteorology 78, 39-69.

Viana, S., Yagüe, C., Maqueda, G., Morales, G., 2007. Study of the surface pressure fluctuations generated by waves and turbulence in the nocturnal boundary layer during SABLES2006 field campaign. Física de la Tierra 19, 55-71http://revistas.ucm.es/index.php/FITE/article/view/FITE0707110055A/11537.

Viana, S., Yagüe, C., Maqueda, G., 2009. Propagation and Effects of a Mesoscale Gravity Wave Over a Weakly-Stratified Nocturnal Boundary Layer During the SABLES2006 Field Campaign. Bound. -Layer Meteorol. 133, 165-188.

Werner, C., Bosveld, F., Vermeulen, A.T., Moors, E., 2006. The role of advection on CO2 flux measurements at the Cabauw tall tower, The Netherlands. Proceedings of the 17th Symposium on Boundary Layers and Turbulence paper JP5.3, 4 p.

Yagüe, C., Viana, S., Maqueda, G., Lazcano, M.F., Morales, G., Rees, J.M., 2007. A study on the nocturnal atmospheric boundary layer: SABLES2006. Física de la Tierra 19, 37-53Available from http://revistas.ucm.es/?s/02144557/articulos/FITE0707110037A.pdf. 


\section{Figures Legend}

Figure 1. Time series of (a) wind speed, (b) wind direction, (c) vertical velocity and (d) air temperature, at different CIBA tower levels during the night 9-10 March, 2003. For vertical velocity starting from $5.6 \mathrm{~m}$, the value is shifted by the amount shown to the right of each time series

Figure 2. Time series of (a) wind speed and wind direction, and (b) vertical velocity and air temperature, at $96.6 \mathrm{~m}$ CIBA tower level, (c) turbulent kinetic energy, and (d) turbulent sensible heat flux, at different CIBA tower level during the night 9-10 March, 2003.

Figure 3. Time-Frequency representation of (a) kinetic energy density, and (b) turbulent sensible heat flux, at different CIBA tower levels during the night 9-10 March, 2003.

Figure 4. Time series of (a) wind direction, (b) wind speed, (c) air temperature, (d) vertical velocity, (e) turbulent kinetic energy, and (f) turbulent sensible heat flux, at different CIBA tower levels during the night 28-29 May, 2003. For vertical velocity starting from $5.6 \mathrm{~m}$, the value is shifted by the amount shown to the right of each time series.

Figure 5. Time-Frequency representation of (a) kinetic energy density, and (b) turbulent sensible heat flux, at different CIBA tower levels during the night 28-29 May, 2003.

Figure 6. Time series of (a) air temperature, and (b) wind velocity, at different Cabauw tower levels during the evening of 20 April, 2004, and (c) vertical profile of wind speed at different hours.

Figure 7. Time series of (a) turbulent kinetic energy, (b) turbulent sensible heat flux, (c) turbulent latent heat flux, and (d) turbulent carbon dioxide flux, at different Cabauw tower levels during the evening of 20 April, 2004.

Figure 8. Time-Frequency representation of (a) turbulent sensible heat flux, (b) turbulent latent heat flux, and (c) turbulent carbon dioxide flux, at different Cabauw tower levels during the evening of 20 April, 2004. 
a)

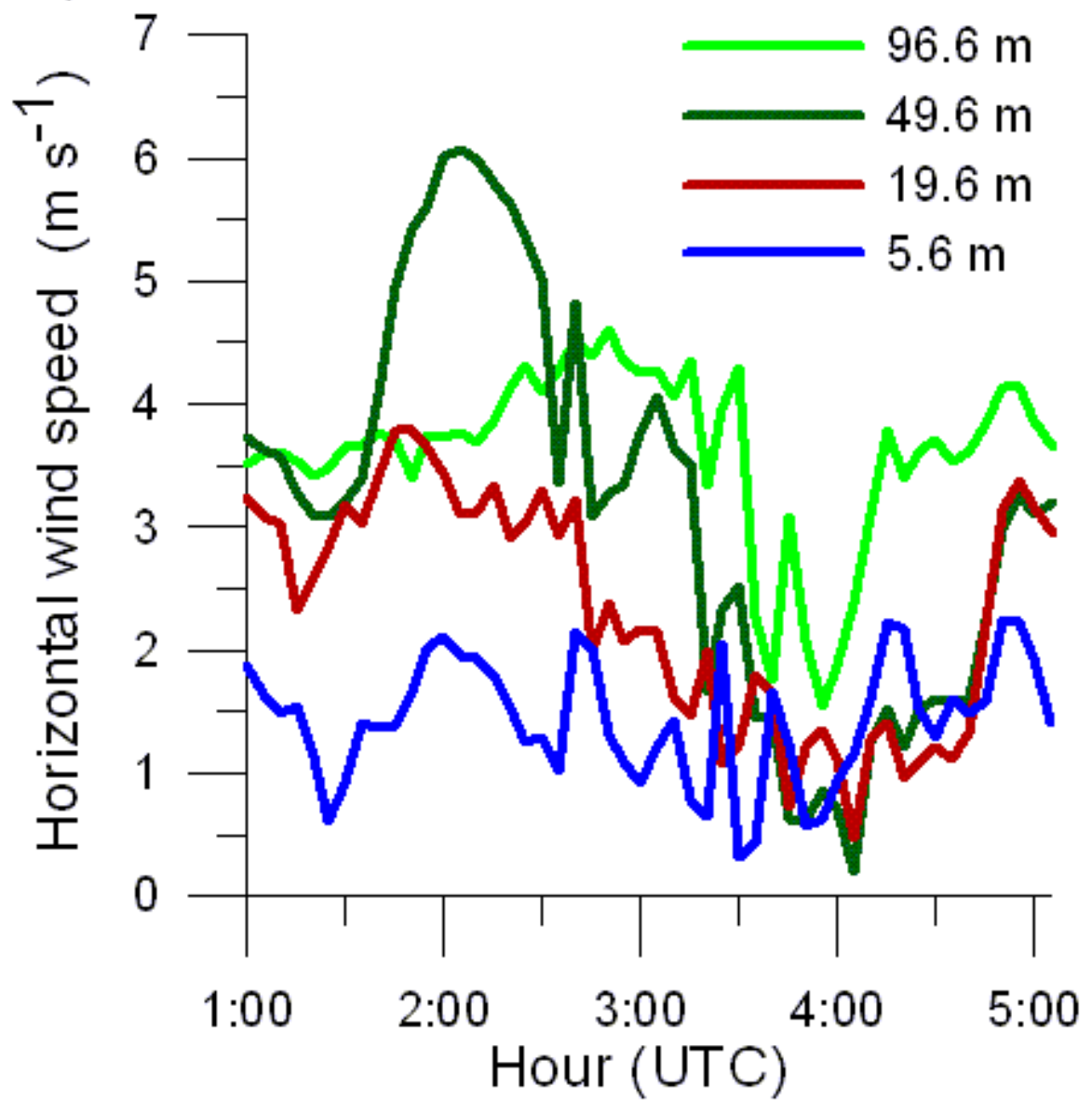

b)

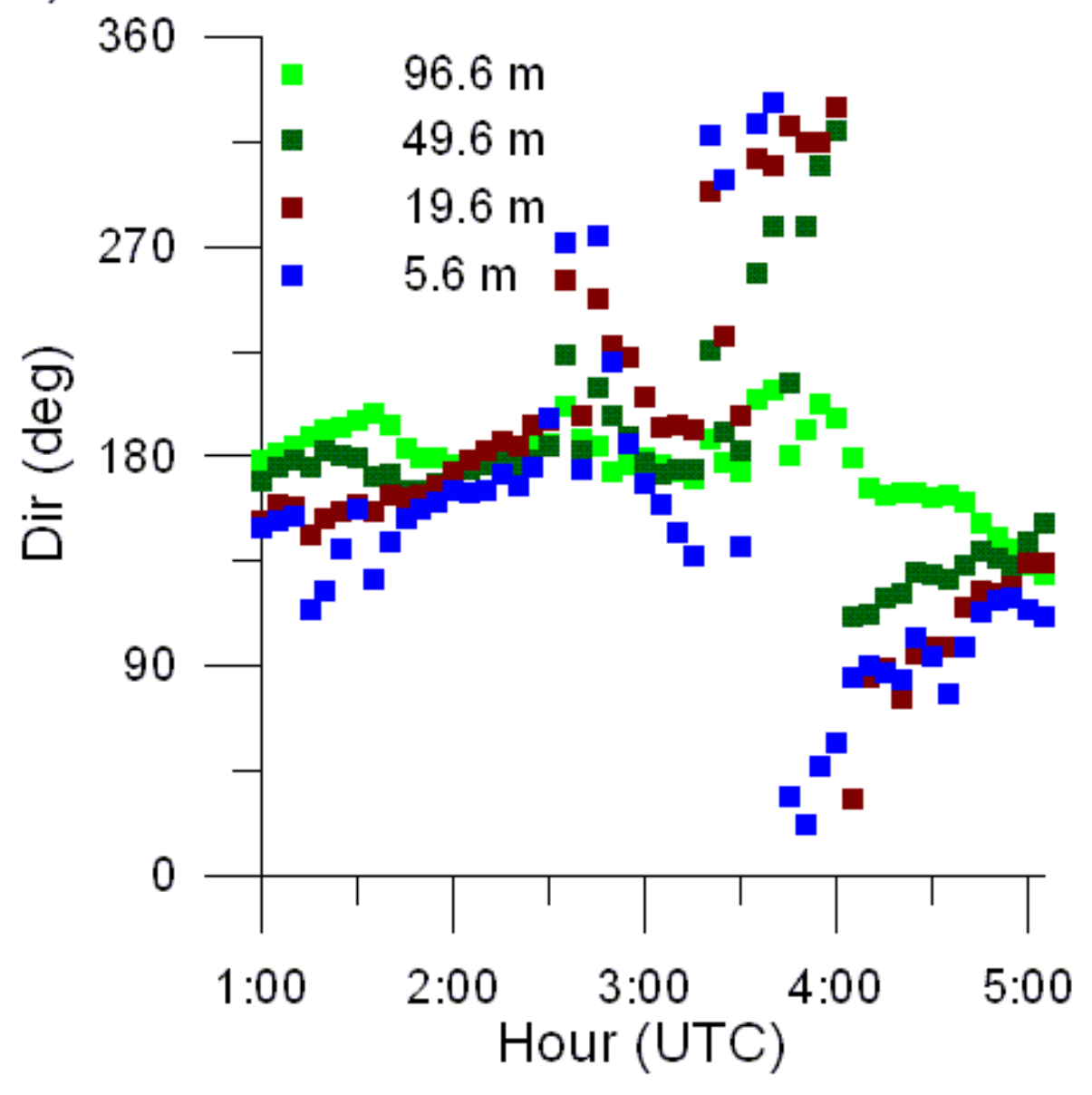

c)



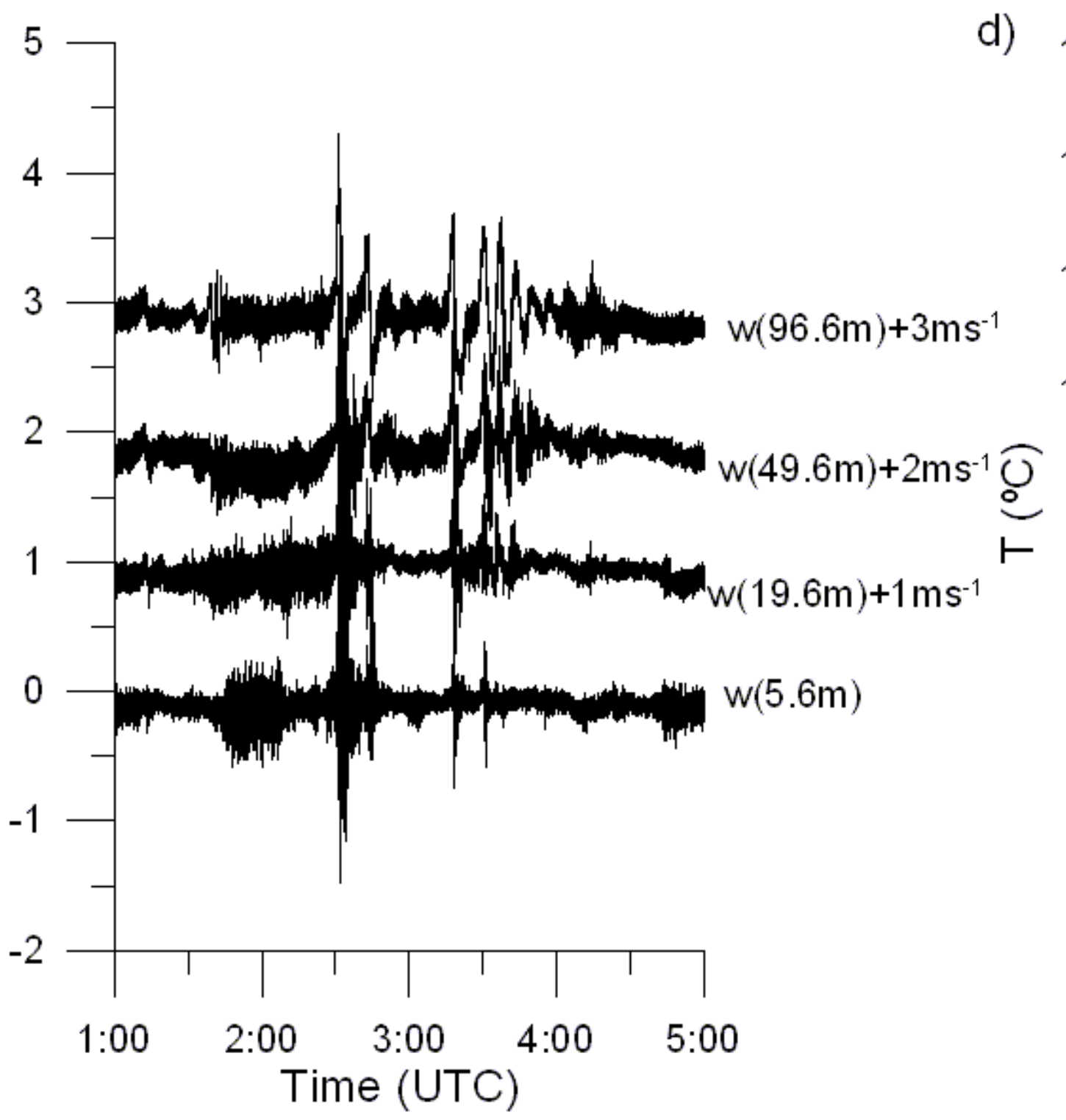

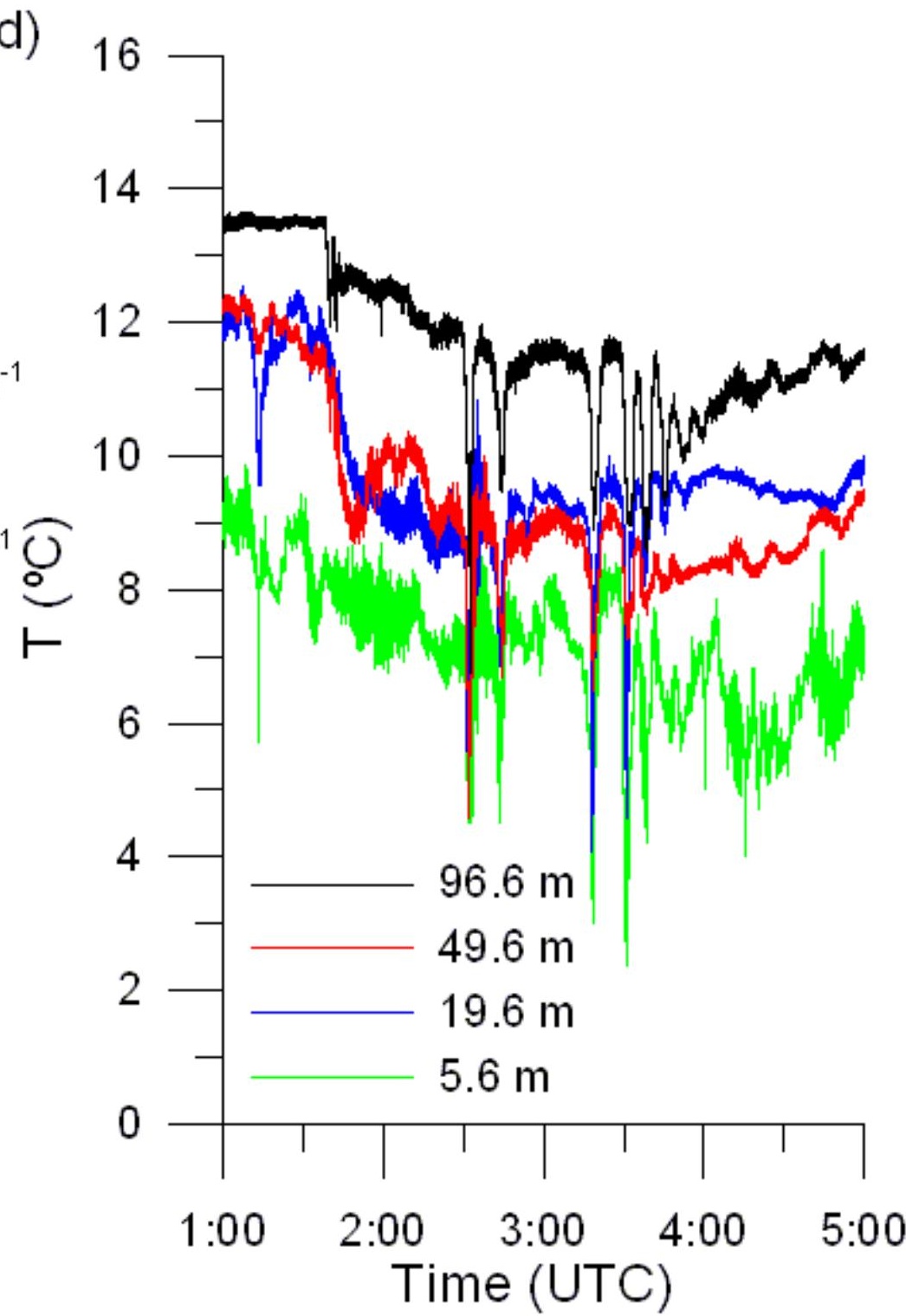




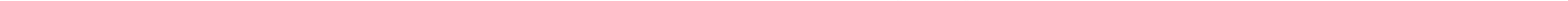


